Revista Tecné, Episteme y Didaxis: TED. Año 2014, Número Extraordinario. ISSN Impreso: 0121-3814, ISSN web: 2323-0126

Memorias, Sexto Congreso Internacional sobre Formación de Profesores de Ciencias. 08 al 10 de octubre de 2014, Bogotá

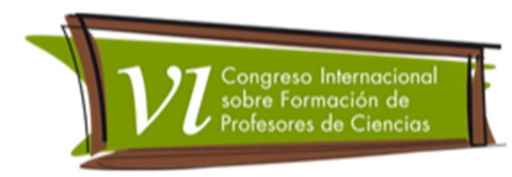

\title{
Dificultades de enseñanza-aprendizaje y su relación con las actitudes hacia la química
}

Ipuz Mónica ' , Parga Diana²

Categoría 2: Trabajos de investigación (en proceso o concluidos).

\section{Resumen}

El presente escrito se enfoca en las actitudes y creencias de profesores y estudiantes que pueden estar generando dificultades en la enseñanza y el aprendizaje de la química; lo cual ha aumentado el desinterés por abordar el conocimiento científico y crear actitudes negativas frente a su estudio, desconociéndose la incidencia de este conocimiento y de la tecnología en el contexto en el que se encuentran los estudiantes.

Este trabajo resalta la necesidad de contextualizar el currículo de química, a partir del conocimiento de las problemáticas socios ambientales que se presentan en la actualidad relacionadas con los adelantos científicos y tecnológicos.

\section{Palabras clave}

Imagen, actitudes, creencias, currículo.

\section{Objetivo}

Establecer las relaciones que pueden darse entre las actitudes de los estudiantes y del profesorado (frente al aprendizaje y enseñanza de la química, hacia su impacto social y ambiental) y el contenido curricular que se está enseñando y aprendiendo.

Este objetivo se desarrollará a partir de actividades de caracterización de las dificultades de enseñanza-aprendizaje, de las actitudes e intereses de estudiantes y de profesores, así como la caracterización del currículo con respecto a los contenidos

\footnotetext{
1 Estudiante de Maestría en Docencia de la Química. Universidad Pedagógica Nacional. Colombia

2 Profesora del Departamento de Química. Universidad Pedagógica Nacional. Colombia
} 
Revista Tecné, Episteme y Didaxis: TED. Año 2014, Número Extraordinario. ISSN Impreso: 0121-3814, ISSN web: 2323-0126

Memorias, Sexto Congreso Internacional sobre Formación de Profesores de Ciencias. 08 al 10 de octubre de 2014, Bogotá

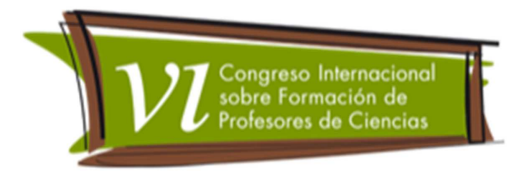

estructurantes de la química, para finalmente diseñar un currículo de química que aborde los aspectos mencionados.

\section{Marco teórico}

Existen factores internos y externos que influyen en el proceso de enseñanza; estos generan dificultades en el momento del aprendizaje y actitudes de rechazo frente a este conocimiento; por lo tanto, se plantean posibles alternativas que pueden llegar a mejorar el aprendizaje de la química a través de la reestructuración del currículo, en donde el componente pedagógica y didáctica se centren en las necesidades de los estudiantes con respecto al conocimiento científico propio de la química y en las necesidades de la educación científica llevando a plantear esta problemática a través de las preguntas:

¿Qué relaciones se pueden dar entre las actitudes de los estudiantes y del profesorado (frente al aprendizaje y enseñanza de la química, y su impacto social y ambiental) y el contenido curricular que se está enseñando y aprendiendo?

¿Qué currículo puede ser generado desde el estudio de las actitudes e intereses de los estudiantes y profesores frente a la educación en química, y que a su vez contemplen las dificultades generadas en la enseñanza y aprendizaje de esta ciencia?

Para tratar de dar respuesta a estos interrogantes se desarrolla un proceso de reconocimiento de los elementos que pueden estar afectando el proceso educativo en el estudio de la química, retomándose estudios desde los diferentes aspectos que se plantean en el trabajo de investigación los cuales son:

Los problemas derivados de la enseñanza por parte de los docentes, producidos por el poco conocimiento propio de las ciencias y de la educación científica, las dificultades en la construcción de un currículo contextualizado a las necesidades de las ciencias y de los estudiantes, así como del conformismo por parte del profesor al creer que sus prácticas de enseñanza son satisfactorias para sus educandos, evitando el cambio en sus prácticas docentes (Ruiz, Martínez y Parga, 2009).

En el trabajo de Martin, Gómez y Gutiérrez (2000) se enuncian acciones como el modo de aplicar el saber desarrollado para solucionar problemas de su entorno; el poco manejo del lenguaje científico y desarrollo de los contenidos, la forma como el docente aborda los contenidos desde el estudio atómico-molecular y macroscópico 
Revista Tecné, Episteme y Didaxis: TED. Año 2014, Número Extraordinario. ISSN Impreso: 0121-3814, ISSN web: 2323-0126

Memorias, Sexto Congreso Internacional sobre Formación de Profesores de Ciencias. 08 al 10 de octubre de 2014, Bogotá

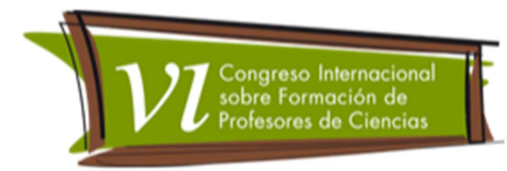

de la materia, lo que puede estar contribuyendo en las dificultades que el estudiante presenta en el momento de diferenciar ambos planteamientos.

La influencia de factores externos también dificultan el aprendizaje de las ciencias, especialmente de la química, debido a la visión de ciencia que los medios de comunicación venden a la comunidad: ciencia contradictoria en la que se le asignan valores como "buena o mala" para el ser humano (Mora y Parga, 2009).

Estos factores mencionados dan a entender que dentro de los aspectos que influyen en el desarrollo educativo de los estudiantes se hace necesario que el docente aborde el conocimiento químico desde:

- La didáctica de la química: que proporciona alternativas frente a los problemas que desde la enseñanza de las ciencias se presentan y que contribuye al desarrollo de la educación científica, identificando dificultades en los estudiantes y docentes. En este sentido, la tabla 1 muestra las principales dificultades de enseñanza y aprendizaje planteados por Pozo, Gómez, Limón, y Sáenz (1991); Martin, Gómez y Gutiérrez (2000) y Ruiz, Martínez y Parga (2009).

Tabla 1. Dificultades de enseñanza aprendizaje de la química

\begin{tabular}{|c|c|c|}
\hline $\begin{array}{l}\text { Dificultades de } \\
\text { enseñanza }\end{array}$ & $\begin{array}{l}\text { Dificultades de } \\
\text { aprendizaje }\end{array}$ & Posibles alternativas de mejoramiento \\
\hline $\begin{array}{l}\text { La creencia del } \\
\text { profesorado sobre cómo } \\
\text { enseñar ciencias }\end{array}$ & $\begin{array}{l}\text { la aplicación de } \\
\text { procedimientos para } \\
\text { resolver problemas } \\
\text { La poca importancia } \\
\text { de un conocimiento } \\
\text { científico básico por } \\
\text { su poca aplicabilidad }\end{array}$ & $\begin{array}{l}\text { Realizar acciones que permitan ver una } \\
\text { ciencia cambiante, que no hay verdades } \\
\text { absolutas y que el desarrollo de } \\
\text { investigaciones permiten estos cambios. } \\
\text { Resaltar la importancia del manejo del } \\
\text { conocimiento químico y la forma que desde } \\
\text { ella se trabaja en la construcción del } \\
\text { conocimiento. } \\
\text { Fomentar el diseño de estrategias de } \\
\text { resolución de problemas que permitan } \\
\text { generar reflexión y toma de decisiones. } \\
\text { La apropiación del docente al currículo de } \\
\text { química y la forma de abordar los } \\
\text { conocimientos para que no sean percibidos } \\
\text { como aislados o descontextualizados. }\end{array}$ \\
\hline
\end{tabular}


Revista Tecné, Episteme y Didaxis: TED. Año 2014, Número Extraordinario. ISSN Impreso: 0121-3814, ISSN web: 2323-0126

Memorias, Sexto Congreso Internacional sobre Formación de Profesores de Ciencias. 08 al 10 de octubre de 2014, Bogotá

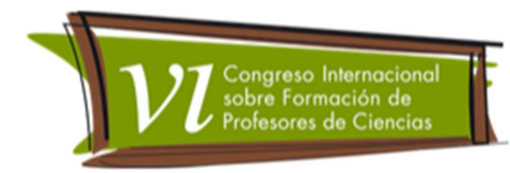

\begin{tabular}{|l|l|l|}
\hline $\begin{array}{l}\text { La concepción de tipo } \\
\text { transmisionista }\end{array}$ & $\begin{array}{l}\text { La aceptación sin } \\
\text { cuestionamiento de lo } \\
\text { que dice el profesor, } \\
\text { los libros de texto, los } \\
\text { medios informáticos y } \\
\text { de comunicación }\end{array}$ & $\begin{array}{l}\text { Establecer diferencias entre el mundo } \\
\text { microscópico, el mundo macroscópico y la } \\
\text { relación que se generan mediante sus } \\
\text { interacciones }\end{array}$ \\
& $\begin{array}{l}\text { La confusión generada } \\
\text { por el manejo de } \\
\text { modelos teóricos y la la } \\
\text { realidad. }\end{array}$ & $\begin{array}{l}\text { y necesidades con las que el estudiante } \\
\text { continúa o inicia sus estudios en la educación } \\
\text { química. }\end{array}$ \\
\hline $\begin{array}{l}\text { El creer que las ciencias } \\
\text { naturales debe mejorar y } \\
\text { facilitar la vida de las } \\
\text { personas a través de la } \\
\text { creación e invención de } \\
\text { tecnologías }\end{array}$ & $\begin{array}{l}\text { La imagen negativa } \\
\text { de la química frente al } \\
\text { rechazo de } \\
\text { aprendizaje de la } \\
\text { misma. }\end{array}$ & $\begin{array}{l}\text { Interpretar las concepciones que los } \\
\text { estudiantes tienen frente a la química como } \\
\text { punto de referencia para orientar las } \\
\text { acciones y analizar los obstáculos que se } \\
\text { puedan generar de estas. }\end{array}$ \\
\hline
\end{tabular}

- Las actitudes hacia el aprendizaje de la química resalta la importancia que tiene conocer los intereses y expectativas de los estudiantes y de los profesores que pueden generar actitudes positivas frente a su proceso de enseñanza y aprendizaje.

- La imagen de la química y la comunicación de las ciencias: el direccionamiento de la química hacia la creación de productos de consumo, tecnología, investigación, salud así como el desarrollo de armas para la defensa de países, ha producido en el imaginario de las personas una química destructiva e incomprensible sin que se haga el cuestionamiento de la utilidad real que se le da y a los problemas que se generan frente al adelanto tecnológico o desarrollo científico; además, la poca comunicación que se genera desde las comunidades científicas frente a estos procesos, sustenta la creencia que este conocimiento es incomprensible por lo que se reduce el interés por su estudio y aumenta la apatía y rechazo (Mora y Parga, 2009).

- Enfoque CTSA: desde los trabajos de Solbes y Vilches (2004), las nuevas tecnologías traen consigo responsabilidades frente a su uso, es por esto que se ha planteado la necesidad de reorientar la educación en ciencias retomando los objetivos planteados desde la alfabetización científica y tecnológica con la finalidad de dar mayor importancia a la incidencia que tienen las personas frente al uso de estas, logrando desarrollar la capacidad de tomar una posición crítica. 
Revista Tecné, Episteme y Didaxis: TED. Año 2014, Número Extraordinario. ISSN Impreso: 0121-3814, ISSN web: 2323-0126

Memorias, Sexto Congreso Internacional sobre Formación de Profesores de Ciencias. 08 al 10 de octubre de 2014, Bogotá

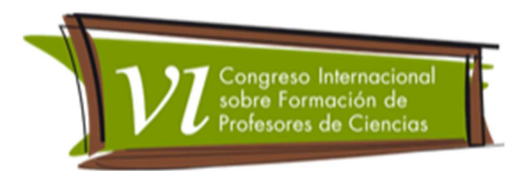

- El trabajo de Martínez y Parga (2013) permite reflexionar sobre la importancia de plantear un discurso a través de los aspectos éticos, sociales, culturales, económico y político que forman parte de la dimensión ambiental, los cuales deben hacerse visibles en el discurso que el docente socialice en sus clases y es necesario que fortalezca y reconstruya su conocimiento didáctico del contenido, para que a partir de él pueda proponer y diseñar un currículo donde las temáticas socio científicas permitan el acercamiento de los estudiantes a las ciencias a través de fuentes más objetivas.

A través de los trabajos mencionados se reconoce la necesidad de diseñar un currículo con el que se logre captar el interés de los estudiantes y desarrollar actitudes favorables para el proceso de enseñanza aprendizaje considerando la estructura, el diseño y modelo curricular (Pérez 2011), más apropiados para abordar la problemática y lograr los objetivos que aquí se plantea.

Para esto, al momento de estructurar y diseñar un currículo es necesario tener en cuenta las recomendaciones dadas por Torres (2011), las cuales van encaminadas a valorar el conocimiento de los alumnos, potenciar la personalidad y las capacidades y emplear estrategias de enseñanza y aprendizaje flexibles y participativos.

\section{Metodología}

La metodología cualitativa que se plantea, permitirá formar parte del proceso que se desarrolle desde la identificación del grupo hasta formar parte de las soluciones, creando reflexión en los participantes de la investigación de la institución Eduardo santos, de la ciudad de Neiva - Huila, en Colombia.

De esta forma, junto con la comunidad se desarrollará el proceso de recogida de datos con técnicas como encuestas, entrevistas semi-estructuradas, análisis de documentos y diario de campo para la realización del seguimiento de las observaciones.

Para lograr un acercamiento a lo que se ha plasmado como objetivo general, se hace necesaria la aclaración de las concepciones y creencias que el docente tiene frente a la enseñanza de las ciencias y las actitudes y concepciones que los estudiantes presentan al momento de aprender. 
Revista Tecné, Episteme y Didaxis: TED. Año 2014, Número Extraordinario. ISSN Impreso: 0121-3814, ISSN web: 2323-0126

Memorias, Sexto Congreso Internacional sobre Formación de Profesores de Ciencias. 08 al 10 de octubre de 2014, Bogotá

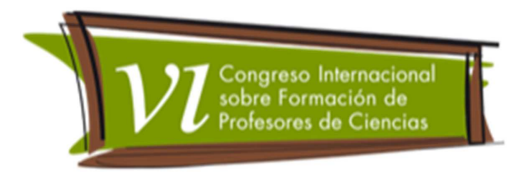

Lo planteado, permitirá tener mayor conocimiento del contexto en el que se desarrolla el proyecto de investigación para que a partir del mismo se pueda diseñar el meso currículo con el que se espera mejorar algunas actitudes de los estudiantes y profesores frente al aprendizaje a la enseñanza de la química.

\section{Conclusiones}

Para desarrollar un estudio pertinente a las necesidades y dificultades planteadas se hace necesario buscar alternativas para lograr cambiar la actitud de los estudiantes hacia el aprendizaje de la química; para esto es necesario la reestructuración del currículo en el que se tenga en cuenta el desarrollo de las temáticas a partir de conceptos estructurantes o centrales, que permitan cambiar la visión de una química en la que se trabajan temáticas desarticuladas con lenguajes difíciles y que a través de la construcción de tramas didácticas, se pueda aportar a mejorar parte de las dificultades presentes; para ello se incluirán en el currículo implicaciones socio científicas (ISC) o socioambientales (ISA) desde las relaciones CTSA, que favorezcan la contextualización de la química y las dificultades que se presentan en el aprendizaje, al generarse una imagen de la química apartada del contexto social.

\section{Referencias bibliográficas}

Martin, M.; Gómez, M.; y Gutiérrez M. (2000). La física y la química en secundaria. Madrid: Narcea S. A.

Martínez, L. y Parga D. (2013). Discurso ético y ambiental sobre cuestiones socio científicas. Colombia: Grupo Dao Digital Ltda.

Mora, W. y Parga, D. (2007). Tramas histórico-epistemológicas en la evolución de la teoría estructural en química orgánica. Tecné, Episteme y Didaxis: TED, 21. Pp. 100 $-117$.

Mora, W. y Parga, D. (2008). El conocimiento didáctico del contenido en química: integración de las tramas de contenido histórico-epistemológicas con las tramas de contexto aprendizaje. Tecné, Episteme y Didaxis: TED, 24. Pp. $56-81$. 
Revista Tecné, Episteme y Didaxis: TED. Año 2014, Número Extraordinario. ISSN Impreso: 0121-3814, ISSN web: 2323-0126

Memorias, Sexto Congreso Internacional sobre Formación de Profesores de Ciencias. 08 al 10 de octubre de 2014, Bogotá

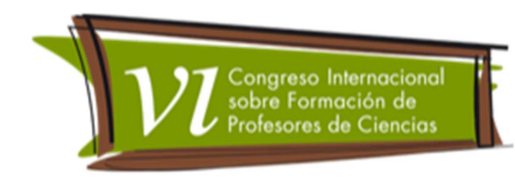

Mora, W. y Parga, D. (2009). La imagen pública de la química y su relación con la generación de actitudes hacia la química y su aprendizaje. Tecné, Episteme y Didaxis: TED, 27. Pp. $67-93$.

Pérez R. (2011). El diseño curricular: componente y modelos. Diseño y desarrollo del currículum. Madrid: Alianza editorial, S.A. Pp. 77 - 97.

Pozo, J.; Gómez, M.; Limon, M. y Sáenz, A. (1991). Procesos cognitivos en la comprensión de las ciencias: Las ideas de los adolescentes sobre la química. Madrid: CIDE.

Ruiz, D.; Martínez, L. y Parga, D. (2009). Creencia de los profesores de preescolar y primaria sobre ciencia, tecnología y sociedad, en el contexto de una institución rural. Tecné, Episteme y Didaxis: TED, 25. Pp. 41-61.

Sánchez G. y Valcarcel M.(2000). ¿Qué tienen en cuenta los profesores cuando seleccionan el contenido de enseñanza? Cambios y dificultades tras un programa de formación. Enseñanza de las ciencias. 18 (3). Pp.423-437.

Solbes, J. y Vilches, A. (2004). Papel de las relaciones entre ciencia, tecnología, Sociedad y ambiente en la formación ciudadana. Enseñanza de las ciencias. 22(3). Pp.337-348.

Torres, J. (201 1). La justicia curricular. El caballo de Troya de la cultura escolar. Madrid: Ediciones Morata, S. L. 